\title{
Household Food Insecurity, Coping Strategies and Adolescent Girls' Dietary Diversity Status in Hossana Town, Ethiopia.
}

Belay Bancha ( $\sim$ banchabelay@gmail.com )

Hossana College of Helath Science https://orcid.org/0000-0002-6180-8754

Legese Petrose

Hossan College of Health Sciences

Begidu Bashe Fanta

Hossana college of Health Sciences

Ashebir Endale

Hossana College of health Science

Romedan Delil

Hossana college of Health science

Mengistu Lodebo

Hossana college of Health science

Research

Keywords: Adolescent girls, micronutrients, Dietary diversity, food security

Posted Date: October 21st, 2020

DOI: https://doi.org/10.21203/rs.2.19588/v2

License: (9) (i) This work is licensed under a Creative Commons Attribution 4.0 International License.

Read Full License 


\section{Abstract}

Background Globally there are 1.8 billion adolescents, comprised of 10-19 years old, represent approximately $20 \%$ of the world's population. In Ethiopia this group represents $20-26 \%$ of general population. Despite the fact that this period is a window of opportunity to break intergenerational cycle of malnutrition, macro and micronutrient deficiencies are among leading health problems in this vulnerable age groups. Moreover, there is scarcity of data on the status of dietary diversity in this segments of the population.

Methods a community based cross sectional study design was employed from May 21-June 20, 2019. Pre-tested structured questionnaire was used for data collection using cluster sampling technique to approach 451 households with adolescent girls. Data was entered in to Epi-Data version 3.1 then exported to SPSS version 23 for analysis. Descriptive and logistic regression analysis were performed. Adjusted Odd Ratios (AOR), along with corresponding 95\% confidence interval (Cl) were used and the level of statistical significance was declared at a p-value of $<0.05$.

Results a total of 434 households with adolescent girls were involved in the study. We found that $41.7 \%$ of households were food insecure, only $57.8 \%$, (C.I.53.5-62.2) of adolescent girls consumed diversified diet, with the mean DDS of $5.38(S D=1.75)$. After adjusting for potential confounders, occupational status of the adolescents' father, (AOR= 0.56, 95\% C.I. 0.32-0.99 and $A O R=0.26,95 \%$ C.I. 0.17-0.47), exposure to televised media (AOR=3.36, 95\% C.I. $=1.55-7.3$ ) and household food security status (AOR=5.09, 95\% C.I. $=3.2-8.08$ ) were significant predictors of dietary diversity among adolescent girls.

Conclusion Significant portion of households were food insecure; practicing ranges of coping strategies which further compromised dietary diversity of adolescent girls. Poor dietary diversity adversely affects micronutrient reserves of to-be a-mother girls; the vicious cycles of malnutrition continues its far fetching effect. Given that adolescence is the second period in life with rapid growth and development, improving dietary status of this sensitive segments of the population are to be an agenda of all concerned bodies.

\section{Background}

Globally, there are 1.8 billion adolescents, comprising 10-19 years old, representing approximately $20 \%$ of the world's population. Of these, $90 \%$ live in low- and middle-income countries (LMICs). In Ethiopia, these groups represent $20-26 \%$ of the population (1-3). Adolescence is the period of most rapid growth second to childhood (4), characterized by rapid transition to adulthood marked by physical and biological growth and development. For instance, 50, 20 and $50 \%$ of adult weight, height, and skeletal mass are gained in this period; hence, optimal nutrition is critical during this period (5-8). Additionally, it is a period of critical window of opportunity to intervene in an intergenerational cycle of malnutrition (3). Addressing the nutritional needs of adolescent girls could be an important step in breaking the vicious cycle of intergenerational malnutrition, chronic diseases, and poverty $(9,10)$. However, adolescents from developing countries are susceptible to nutritional deficiencies due to early childhood nutritional insults 
(11) and adverse environmental conditions, including food insecurity, which could impact their development and wellbeing (5).

Dietary diversity score (DDS), a proxy for adequate micronutrient density of foods (12), is defined as the number of individual food groups consumed over a given period of time. Along with food variety and consumption of animal source foods, dietary diversity is an indicator commonly used to assess intake and quality of diet at the household or individual level. In addition, DDS is a measure of food security, nutrition information, early warning systems and targets of intervention at the global or national level $(6,13)$. It has been propagated as a health-beneficial component of dietary behavior and complements the concept of exploratory dietary patterns. In LMICs, dietary diversification has been examined, primarily concerning malnutrition-related health outcomes (14).

The overall nutritional quality of the diet is improved with diverse diets. Therefore, diversity in the diet is important to meet the requirements for energy and other essential micronutrients, especially for those who are at risk of nutrition deficiencies (15). Dietary diversity is a predictor of observed undernutrition (16).

Despite considerable efforts to decrease its prevalence, the health and nutritional status of adolescents has seen limited improvement over the past 50 years $(8,17)$.

It is estimated that micronutrient deficiency is a global public health problem affecting two billion people worldwide $(10,18)$, of which 500 million are women of reproductive age (19). Although diet-related health problems affect both sexes and all age groups, they are a major public health problem among women (20), especially among adolescent girls (21). It can result in diminished physical growth, cognitive and motor development, poor performance in school and productivity, and affect reproduction $(21,22)$. Considering the burden of suboptimal dietary intake, the promotion of adequate dietary diversity has become a global concern (6).

In recognition of its health consequences, in 2012, the 65th World Health Assembly endorsed a 50\% reduction in the burden of micronutrient deficiency in women of reproductive age by 2025, from 2011 levels. Ethiopia has also been striving to curve the high burden of micronutrient deficiencies through implementing national nutritional programs and strategies. However, the initiatives have been targeting only pregnant women and children aged 6-59 months; under-representing adolescent girls. Additionally, the status of dietary diversity is not investigated in this vulnerable age segment of the population.

\section{Methods}

\section{Study setting, design and sampling}

A community-based cross-sectional study design was employed in Hosanna Town, Hadiya Ethiopia.

Sample size was computed with the assumptions of a single population proportion formula to detect at 
least $26.8 \%$ dietary diversity (23), $95 \%$ significance level, $5 \%$ margin of error, $10 \%$ nonresponse rate and design effect of 1.5; the final sample size was $(301 * 1.5)=451$.

$$
\begin{gathered}
\mathrm{n}=\frac{(\mathrm{z} \alpha / 2)^{2} \times \mathrm{p}(1-\mathrm{p})}{\mathrm{d}^{2}}=\frac{\left(\frac{\mathrm{z} \alpha}{2}\right)^{2} \times 0.268(1-0.268)}{(0.05)^{2}} \\
=\frac{(1.96)^{2} \times 0.196}{0.0025}=301
\end{gathered}
$$

where

- $\mathrm{n}=$ sample size

- $z \alpha / 2=95 \%$ CI with two tailed test

- $\mathrm{p}=$ population proportion

- $\mathrm{d}=$ margin of error

A cluster sampling method was used; after random selection of three Kebele (the least administrative structure), we obtained the total number of predefined distinct clusters (Mender) (smallest cluster within an administrative Kebele) with the size of the adolescent girls for each "Mender". Afterwards, the required numbers of clusters (Mender) were assigned to kebeles by ENA software using the probability proportional to population size (PPS) method. In this method, larger settlements have a higher chance of being selected as clusters compared to smaller settlements because the probability of selection is proportional to the population size of the settlement. Once again, computer-generated random numberspecific clusters corresponding to each kebele were assigned. Finally, all households (HHs) from identified clusters with adolescent girls were selected for data collection.

\section{Data collection tools and procedures}

The questionnaire was adapted from the Ethiopian Demographic and Health Survey 2016 (EDHS, 2016) and WHO/FAO guidelines (24). A structured Amharic version questionnaire was administered to assess socioeconomic and demographic factors. Household food security status was determined using the household food insecurity access scale (HFIAS) developed by Food and Nutrition Technical Assistance (FANTA) (25). We used 24-H dietary recall in the preceding day to assess dietary diversity scores among adolescents. Groups of foods were prepared from FANTA/FAO and further categorized into ten food 
groups. The dietary diversity score was created as a summary measure using the consumption of 5 or more food groups as adequate (6); otherwise, it is inadequate to apply a logistic regression model.

\section{Data quality management}

To assure the quality of data, data collector supervisors were trained for two days on the clarity of tools and overall data collection procedures. A structured questionnaire was prepared in English, translated to Amharic and back translated to English by bilingual experts to check consistency. A pretest was performed on $5 \%$ of the sample size, and this was not included in the actual data. Cronbach's alpha was computed to assess the internal consistency; hence, possible modification to the tool was considered based on pretest results. Data collection was carried out by trained diploma nurses under supervision. All collected data were returned to Pls and checked and cleaned for consistency and completeness; discussion was made on a daily basis.

\section{Data analysis}

Data were entered into Epi- Data version 3.1 and then exported to Statistical Package for Social Science (SPSS) version 23 for analysis. Before analysis of missing values, new categories and normality for continuous variables were checked. The $\mathrm{HH}$ wealth index was computed by principal component analysis (PCA) based on household assets and housing quality variables that were adapted from EDHS2016 (26). Descriptive statistics were performed for each variable, including the outcome variables. DDS status was dichotomized using five food groups as cut off values to fit for the logistic regression model. First, bivariate analysis was performed to identify candidate variables for multivariable logistic regression. Variables with a $p$-value of $<0.25$ in bivariate analysis were regarded as candidates for multivariate analysis. Finally, multivariable logistic regression was fitted to the data to identify predictors of DDS among study participants. Adjusted odds ratios (AORs), along with corresponding $95 \%$ confidence intervals (Cls), were used in the writing results. The level of statistical significance was declared at a pvalue of $<0.05$.

\section{Results}

\section{Sociodemographic characteristics}


A total of $434 \mathrm{HHs}$ were included in the analysis, yielding a response rate of $96.2 \%$. Of the total adolescent girls, 130 (30\%), 151 (34.8\%) and 133 (35.3\%) were in their early, middle and late adolescence age, respectively. We found that of the total participants, $61.1 \%$ were protestant by religion and $78.8 \%$ were Hadiya by Ethnicity. The occupational and educational status of parents, household family size and wealth index were assessed (Table 1).

\section{Table 1: Here}

Concerning access to information, more than a quarter (26.5\%) and approximately $40 \%$ of adolescent girls listen to radio and watch television at least once a week, respectively.

\section{Household food security status}

Of the total HHs under the study, 253 (58.3\%) were food secure, whereas the remaining $181(41.7 \%)$ were food insecure. Food insecure HHs were further categorized into different degrees of food insecurity: mildly food insecure 48 (11.1\%), moderately food insecure 59 (13.6\%) and severely food insecure 74 $(17 \%)$.

When food insecurity exists at the $\mathrm{HH}$ level, shifting to less expensive and poor quality food $(73.5 \%)$, reducing non-food expenditures (53\%), reducing the amount of consumed meal (41\%) and cutting the number of meals ( $40 \%)$ were among the major coping strategies used by the household.

\section{Dietary Diversity Status of Adolescent Girls}

Of the total adolescents involved in the study, 251 (57.8\%, C.I.53.5-62.2) consumed a diversified diet with a mean DDS of 5.38 (1.75) 24 hours preceding the survey date. Almost all of the participants $(97.5 \%)$ consumed grains, white roots and tubers, and plantains followed by pulses (87.6\%) and dark green leafy vegetables $(77.2 \%)$. The least consumed diets were nuts (22\%) and meat, poultry and fish $(22.4 \%)$ (Table 2).

Table 2:Here

\section{Bivariate analysis to identify candidate variables}

In bivariate analysis, ten potential covariates were identified for the multivariable logistic regression model: age of adolescent girls, living with both parents, educational status of mother, educational status of father, maternal occupation, paternal occupation, adolescents listening to radio, adolescents watching television, HHs wealth index and HHs food security status identified at a p-value $<0.25$.

\section{Predictors of dietary diversity status}


Potential covariates identified in bivariate analyses were entered into a multivariable logistic regression model using the backward removal method to adjust for potential confounders in predicting the outcome.

After adjusting for the other occupational statuses of adolescents' fathers, adolescents' exposure to televised information and household food security status showed statistically significant associations with the dietary diversity status of the population under the study.

Estimates obtained through multivariable logistic regression showed that the odds of consuming a diversified diet are $44 \%$ and $74 \%$ lower when the occupation of adolescent girls' fathers is merchant and other, respectively, compared to their counterparts from the employee father (AOR= 0.56, 95\% C.I. 0.320.99 and $A O R=0.26,95 \%$ C.I. 0.17-0.47).

The likelihood of consuming a diversified diet among adolescent girls with exposure to television media is approximately 3.4 times more likely than their counterparts (AOR=3.36, 95\% C.I. $=1.55-7$. 3).

Furthermore, there was a five-fold increase in the odds of consuming a diversified diet among adolescent girls living in food-secure HHs (AOR=5.09, 95\% C.I. $=3.2-8.08)$ (Table 3 )

Table 3:Here

\section{Discussion}

The Sustainable Development Goals (SDGs) call for efforts to eliminate world hunger and malnutrition in all forms by 2030 and ensure the access of all people to nutritious and abundant food. However, there is a problem of access to it, making close to 800 million chronically hungry despite sufficient food production in the world $(27,28)$.

Despite global initiatives and sufficient food production, our study reported that approximately $42 \%$ of $\mathrm{HH}$ s were food insecure. This is in line with reported $37.2-44.4 \% \mathrm{HH}$ food insecurity in the country $(29,30)$; however, the status of food insecurity is much higher than reported $14 \%$ (3) and lower than $75 \%$ of Birhane et al (31) and $80.5 \%$ of Kenya (32). These inconsistencies could be explained by socioeconomic and methodological differences. In the context of food insecurity, we found that HHs use different coping strategies to address difficulties. This is supported by findings from qualitative and quantitative studies $(28,31-33)$.

Our study showed that substantially less than two-thirds of adolescent girls consumed diversified diets. This intake is lower than reports from some parts of the country that documented $63.3-75.5 \%$ of adolescents had adequate dietary diversity $(6,29,34)$, but it is higher than studies in the Gurage Zone (23). The possible explanation for this variation could be due to the use of different cut-offs to declare the consumption of diversified diets in the population.

After controlling for the confounding effects of others, the occupational status of adolescents' fathers, adolescents' exposure to televised information, and household food security status predicted dietary diversity status among adolescent girls. This study identified that adolescent girls whose fathers are 
merchants and of other occupations are less likely to consume diversified diets in comparison to their counterparts from employed fathers. This could be explained by the lack of time to stay at home due to busy working schedules (35); as a result, minimal care is expected. In other words, men can contribute to improving household nutrition security by reducing the consumption of food away from the home (36). Moreover, male involvement in affairs of family care, including nutrition, is found to be a determinant (37).

In this study, it was found that adolescent girls who watch television at least once a week are more likely to consume diversified diets. This may be best explained as television media have more favorable associations with recommended levels of lifestyle behaviors (38). Adherence to a healthy dietary recommendation is increased with greater exposure to the information delivered by different mass media (39). As a result, individuals with access to health-promoting information are supposed to have better nutritional knowledge that could be translated to practice.

The current study identified that $\mathrm{HH}$ food security status determines the dietary diversity of adolescent girls in the study setup. This is in line with other studies that reported that the likelihood of having adequate dietary diversity was higher among adolescents from food-secured $\mathrm{HHs}$; food insecurity predisposes people to relay on an undiversified diet $(13,40)$, a range of coping strategies, as evident in this study.

In contrast to the hypothesis, surprisingly, parental education (23) was not associated with the dietary diversity of adolescents after controlling for the confounding effects of others. This may signal that nutritional knowledge is lacking in the curricula of formal education. Household wealth status may be associated with both $\mathrm{HH}$ food security and dietary diversity but not in the causal pathway; hence, it is not a true predictor of dietary diversity in this study.

\section{Conclusion}

A significant portion of $\mathrm{HHs}$ are food insecure, practicing ranges of coping strategies that further compromise the dietary diversity of adolescent girls in the household. The role of media, paternal occupation, and household food security had statistically significant correlations with the dietary diversity of adolescent girls. Poor dietary diversity adversely affects micronutrient reserves of to-be amother girls; the vicious intergenerational cycles of malnutrition continue its far fetching effect. Because adolescence is the second period in life during which rapid growth and development occurs, improving the dietary status of these sensitive segments of the population is an agenda of all concerned bodies. Based on this finding, we have the following recommendations.

In the era of information revolution, media should take a leading role in transmitting health-promoting messages, including dietary recommendations. Scientific communities should be able to influence the media in favor of healthy dietary recommendations with the aim of breaking the intergenerational cycle of malnutrition. Given that parental monitoring of dietary intake is significant, parents spending much time out of home should give due attention to watching the dietary intake of adolescent girls. 
Governmental and nongovernmental organizations working in nutrition-sensitive and nutrition-specific programs should perform their tasks in averting an unacceptably high prevalence of household food insecurity. We recommend nutrition in the educational curricula, as we have observed that educational status lacks a statistical relation to dietary diversity. Despite significant contributions to filling this gap, we recognize the following limitations: qualitative dietary information may not correlate with nutrient adequacy, and intrahousehold dietary diversity was not assessed, which could reveal gender differences in the context.

\section{List Of Abbreviations}

$\mathrm{AOR}=$ adjusted odds ratio; $\mathrm{Cl}=95 \%$ confidence interval; $\mathrm{COR}=$ crude odds ratio; DDS=dietary diversity score; EDHS=Ethiopian demographic and health survey; HHs=households; LMICs=low- and middle-income countries; PCA=principal component analysis.

\section{Declarations}

\section{Ethics approval and consent to participate}

The study was approved by the ethical Review Board of Hossana College of Health Science. All the study participants were informed about the purpose of the study, and oral consent was obtained before interviews. For ages less than 18 years, ascent was prepared. Respondents were informed that they had the right to refuse or terminate the interview, and the information provided by each respondent was kept confidential.

\section{Consent for publication}

Not applicable for this section.

\section{Availability of data and materials}

The datasets used during the current study are available from the corresponding author on reasonable request.

\section{Competing interests}

The authors declare that they have no competing interests.

\section{Funding}


Hossana College of Health Science funded this research, but the funding organization has no effect on the scientific procedure of this paper.

\section{Authors' contributions}

BB was involved in the design, conduct, analysis, interpretation and drafting of the manuscript; LP was involved in the design, analysis, interpretation and revision of the manuscript. BBF, AE and RD were involved in the design, analysis and interpretation. ML revised and edited the manuscript for the final submission. All authors read and approved the final manuscript.

\section{Acknowledgements}

It is our sincere pleasure to acknowledge the Hossana College of Health Science, Research and Publication Directorate for facilitation of this research. We are grateful to all study participants, supervisors and data collectors without which this work would not take the current shape.

\section{References}

1. Christian P, Smith R. Adolescent Undernutrition: Global Burden, Physiology , and Nutritional Risks. Nutr Metab. 2018;72:316-28.

2. Melaku YA, Zello GA, Gill TK, Adams RJ, Shi Z. Prevalence and factors associated with stunting and thinness among adolescent students in Northern Ethiopia: a comparison to World Health Organization standards. Arch Public Heal [Internet]. 2015;1-11. Available from: http://dx.doi.org/10.1186/s13690-015-0093-9

3. Gonete KA, Tariku A, Wami SD, Derso T. Prevalence and associated factors of anemia among adolescent girls attending high schools in Dembia District, Northwest. Arch Public Heal [Internet]. 2018;76(79):1-9. Available from: https://doi.org/10.1186/s13690-018-0324-y

4. Tesfaye M, Yemane T, Adisu W, Asres Y, Gedefaw L. Anemia and iron deficiency among school adolescents: burden, severity, and determinant factors in southwest Ethiopia. Adolesc Health Med Ther. 2015;189-96.

5. Belachew T, Hadley C, Lindstrom D, Getachew Y, Duchateau L, Kolsteren P. Food insecurity and age at menarche among adolescent girls in Jimma Zone Southwest Ethiopia: a longitudinal study. Reprod Biol Endocrinol [Internet]. 2011;9(1):125. Available from: http://www.rbej.com/content/9/1/125

6. Birru SM, Tariku A, Belew AK. Improved dietary diversity of school adolescent girls in the context of urban Northwest Ethiopia: 2017. Ital J Pediatr [Internet]. 2018;44(48):1-6. Available from: https://doi.org/10.1186/s13052-018-0490-0

7. Teji K, Dessie Y, Assebe T, Abdo M. Anaemia and nutritional status of adolescent girls in Babile District, Eastern Ethiopia. Pan Afr Med J. 2016;8688:1-10. 
8. Akseer N, Al-gashm S, Mehta S, Mokdad A, Bhutta ZA. Global and regional trends in the nutritional status of young people: a critical and neglected age group. Ann N Y Acad Sci. 2017;1393:3-20.

9. Lassi ZS, Mansoor T, Salam RA, Bhutta SZ, Das JK, Bhutta ZA. Review of nutrition guidelines relevant for adolescents in low- and middle-income countries. Ann N Y Acad Sci. 2017;1393:51-60.

10. Krebs N, Bagby S, Bhutta ZA, Dewey K, Fall C, Gregory F, et al. International summit on the nutrition of adolescent girls and young women: consensus statement. In: ANNALS OF THE NEW YORK ACADEMY OF SCIENCES. 2017. p. 3-7.

11. Fatima F, Hafeez A, Yaqoob A. Nutritional assessment of adolescent girls living in Cherah Union Council. 2014;1220-4.

12. CSA of FDRE. Demographic and Health Survey 2016. Addis Ababa: CSA; 2016.

13. Belachew T, Lindstrom D, Gebremariam A, Hogan D, Lachat C, Huybregts L, et al. Food Insecurity , Food Based Coping Strategies and Suboptimal Dietary Practices of Adolescents in Jimma Zone Southwest Ethiopia. PLoS One. 2013;8(3):1-9.

14. Danquah I, Galbete C, Meeks K, Nicolaou M, Klipstein K, Addo J, et al. Food variety, dietary diversity , and type 2 diabetes in a multi - center cross - sectional study among Ghanaian migrants in Europe and their compatriots in Ghana: the RODAM study. Eur J Nutr. 2018;57(8):2723-33.

15. Rathnayake KM, Madushani PAE, Silva K. Use of dietary diversity score as a proxy indicator of nutrient adequacy of rural elderly people in Sri Lanka. BMC Res Notes. 2012;5(469):2-7.

16. Roba KT, Abdo M, Tolass Wakayo. Nutritional Status and Its Associated Factors among School Adolescent Girls in Adama City , Central Ethiopia. J Nutr Food Sci. 2016;6(3):4-11.

17. Rao S, Joshi S, Bhide P, Puranik B, Asawari K. Dietary diversification for prevention of anaemia among women of childbearing age from rural India. Public Health Nutr. 2013;17(4):939-47.

18. Gebremedhin S, Samuel A, Mamo G, Moges T, Assefa T. Coverage, compliance and factors associated with utilization of iron supplementation during pregnancy in eight rural districts of Ethiopia: a cross-sectional study. 2014;1-8.

19. Abdullahi H, Gasim GI, Saeed A, Imam AM, Adam I. Antenatal iron and folic acid supplementation use by pregnant women in Khartoum, Sudan. BMC Res Notes. 2014;7(498):2012-5.

20. Asres Y, Yemane T, Gedefaw L. Determinant Factors of Anemia among Nonpregnant Women of Childbearing Age in Southwest Ethiopia: A Community Based Study. Int Sch Res Not. 2014;2014.

21. Divakar H, Dutta S, Kulkarni B, Divakar G V. ANAEMIA ERADICATION IN ADOLESCENTS- A NEW HOPE WITH WEEKLY IRON FOLIC ACID SUPPLEMENTATION ( WIFS)(PILOT STUDY). J Evid Based Med Heal. 2017;4(17):968-73.

22. Stevens GA, Finucane MM, De-regil LM, Paciorek CJ, Flaxman SR, Branca F, et al. Global , regional , and national trends in haemoglobin concentration and prevalence of total and severe anaemia in children and pregnant and non-pregnant women for 1995 - 2011: a systematic analysis of population-representative data. Lancet Glob Heal. 2012;1:e16-25. 
23. Worku M, Hailemicael G, Wondmu A. Dietary Diversity Score and Associated Factors among High School Adolescent Girls in Gurage Zone , Southwest Ethiopia. World J Nutr Heal. 2017;5(2):41-5.

24. Minimum Dietary Diversity for Women A Guide to Measurement. Rome; 2016.

25. Coates J. Household Food Insecurity Access Scale (HFIAS) for Measurement of Food Access: Indicator Guide [Internet]. 2007. Available from: www.fantaproject.org

26. Ethiopia Demographic and Health Survey 2016:Central Statistical Agency(CSA) Addis Ababa, Ethiopia. The DHS Program ICF Rockville, Maryland, USA;

27. Bi J, Liu C, Li S, He Z, Chen K, Luo R, et al. Dietary Diversity among Preschoolers: A Cross-Sectional Study in Poor, Rural, and Ethnic Minority Areas of Central South China Jieying. Nutrients. 2019;11(558):1-12.

28. Kisi MA, Tamiru D, Teshome MS, Tamiru M, Feyissa GT. Household food insecurity and coping strategies among pensioners in Jimma. BMC Public Health [Internet]. 2018;18(1373):1-8. Available from: https://doi.org/10.1186/s12889-018-6291-y

29. Birru SM, Belew AK, Tariku A. One in three adolescent schoolgirls in urban northwest Ethiopia is stunted. Ital J Pediatr [Internet]. 2018;44(32):1-8. Available from: https://doi.org/10.1186/s13052018-0459-z

30. Wassie MM, Gete AA, Yesuf ME, Alene GD, Belay A. Predictors of nutritional status of Ethiopian adolescent girls: a community based cross sectional study. BMC Nutr. 2015;1(20):1-7.

31. Birhane T, Shiferaw S, Hagos S, Mohindra KS. Urban food insecurity in the context of high food prices: a community based cross sectional study in Addis Ababa, Ethiopia. BMC Public Health [Internet]. 2014;14(680):1-8. Available from: http://www.biomedcentral.com/1471-2458/14/680

32. Macharia TN, Ochola S, Mutua MK. Association between household food security and infant feeding practices in urban informal settlements in Nairobi , Kenya. J Dev Orig Heal Dis. 2018;9(1):20-9.

33. Fatmaningrum D, Roshita A, Februhartanty J. Coping strategies for food insecurity among adolescent girls during the lean season in East Nusa Tenggara, Indonesia : a qualitative study. $\mathrm{Br} \mathrm{J}$ Nutr. 2016;116(S1):S42-8.

34. Tadege M, Id E, Wassie MM, Teferra AS. Anemia and associated factors among adolescent girls living in Aw-Barre refugee camp, Somali regional state, Southeast. PLoS One [Internet]. 2018;13(10):1-12. Available from: https://doi.org/10.1371/journal.pone.0205381

35. Haerens L, Bourdeaudhuij I De, Barba G, Eiben G, Fernandez J, Hebestreit A, et al. Developing the IDEFICS community-based intervention program to enhance eating behaviors in 2- to 8-year-old children: findings from focus groups with children and parents. Health Educ Res. 2009;24(3):38193.

36. Ochieng J, Afari-sefa V, Lukumay PJ, Dubois T. Determinants of dietary diversity and the potential role of men in improving household nutrition in Tanzania. PLoS One. 2017;12(12):1-18.

37. Abate KH, Belachew T. Women 's autonomy and men 's involvement in child care and feeding as predictors of infant and young child anthropometric indices in coffee farming households of Jimma Zone, South West of Ethiopia. PLoS One. 2017;12(3):1-16. 
38. Beaudoin CE, Hong T. Health information seeking, diet and physical activity: An empirical assessment by medium and critical demographics. Int J Med Inform [Internet]. 2011;80(8):586-95. Available from: http://dx.doi.org/10.1016/j.ijmedinf.2011.04.003

39. Bonaccio M, Di A, Costanzo S, Lucia F De, Olivieri M, Benedetta M, et al. Nutrition knowledge is associated with higher adherence to Mediterranean diet and lower prevalence of obesity . Results from the Moli-sani study q Author's personal copy. Anthropol Rev. 2013;68:139-46.

40. Tariku A, Gonete KA, Bikes GA, Alemu K. Household food insecurity predisposes to undiversified diet in northwest Ethiopia: finding from the baseline survey of nutrition project, 2016. BMC Res Notes [Internet]. 2019;12(14):1-7. Available from: https://doi.org/10.1186/s13104-019-4083-9

\section{Annex}

Table 1: Household and/or adolescent sociodemographic characteristics in Hossana town, $2019(n=434)$ 


\begin{tabular}{|c|c|c|c|}
\hline \multirow[t]{3}{*}{ Adolescent girls age category } & Early adolescent & 130 & 30 \\
\hline & Middle Adolescent & 151 & 34.8 \\
\hline & Late adolescent & 153 & 35.2 \\
\hline \multirow[t]{2}{*}{ Ever attended school } & Yes & 429 & 98.8 \\
\hline & No & 5 & 1.2 \\
\hline \multirow[t]{4}{*}{ Religion } & Protestant & 265 & 61.1 \\
\hline & Orthodox & 99 & 22.8 \\
\hline & Muslim & 37 & 8.5 \\
\hline & others & 33 & 7.6 \\
\hline \multirow[t]{4}{*}{ Ethnicity } & Hadiya & 342 & 78.8 \\
\hline & Kembata & 53 & 12.2 \\
\hline & Siltie & 28 & 6.5 \\
\hline & other & 11 & 2.5 \\
\hline \multirow[t]{4}{*}{ Educational status of adolescent's mother } & No formal education & 75 & 17.7 \\
\hline & Primary (1-8 grade) & 227 & 48.8 \\
\hline & $9-12$ grade' & 74 & 17.5 \\
\hline & Graduate & 68 & 16 \\
\hline \multirow[t]{4}{*}{ Educational status of Adolescent's father $(n=423) a^{*}$} & No formal education & 36 & 8.5 \\
\hline & Primary (1-8 grade) & 104 & 24.7 \\
\hline & $9-12$ grade' & 132 & 31.3 \\
\hline & Graduate & 150 & 35.5 \\
\hline \multirow[t]{7}{*}{ Occupation of mother $(n=421)$} & Gov't employee & 78 & 18.5 \\
\hline & NGO & 17 & 4 \\
\hline & Hired in private sector & 24 & 5.7 \\
\hline & Merchant & 104 & 24.7 \\
\hline & Housewife & 182 & 43.2 \\
\hline & Daily labourer & 8 & 1.9 \\
\hline & Other & 8 & 1.9 \\
\hline
\end{tabular}




\begin{tabular}{llcc} 
Occupation of father $(n=423) a^{*}$ & \multicolumn{1}{l}{ Gov't employee } & 158 & 37.4 \\
\cline { 2 - 4 } & NGO & 24 & 5.7 \\
\cline { 2 - 4 } & Hired in private sector & 19 & 4.5 \\
\cline { 2 - 4 } & Merchant & 88 & 20.8 \\
\cline { 2 - 4 } & Farmer & 49 & 11.6 \\
\cline { 2 - 4 } & Daily labourer & 18 & 4.3 \\
\cline { 2 - 4 } & Others & 67 & 15.8 \\
\hline House hold family size & $\leq 5$ & 185 & 42.6 \\
\cline { 2 - 4 } & $>5$ & 146 & 57.4 \\
\hline HH wealth index category & highest & 133 & 35.3 \\
\hline & middle & 135 & 31.1 \\
\hline
\end{tabular}

Table 2: Coconsumption of food groups by adolescent girls using the 24-h recall method in Hossana Town, 2019

\begin{tabular}{lcc}
\hline Types of Diet & Frequency & $\%$ \\
\hline Grains, white roots and tubers, and plantains & 423 & 97.5 \\
\hline Pulses (beans, peas and lentils) & 380 & 87.6 \\
\hline Nuts and seeds & 95 & 21.9 \\
\hline Dairy & 230 & 53.0 \\
\hline Meat, poultry and fish & 97 & 22.4 \\
\hline Eggs & 166 & 38.2 \\
\hline Dark green leafy vegetables & 335 & 77.2 \\
\hline Other Vitamin A-rich fruits and vegetables & 248 & 57.1 \\
\hline Other vegetables & 195 & 44.9 \\
\hline Other fruits & 160 & 36.9 \\
\hline
\end{tabular}


Table 3:Fctors associated with dietary diversity score among adolescents in Hossana Town, 2019

\begin{tabular}{|c|c|c|c|c|c|c|c|}
\hline & \multirow[t]{2}{*}{$\begin{array}{l}\text { Variable } \\
\text { category }\end{array}$} & \multicolumn{2}{|c|}{$\begin{array}{c}\text { Dietary diversity } \\
\text { status }\end{array}$} & \multirow[t]{2}{*}{$\begin{array}{l}\operatorname{COR}(95 \% \\
\quad \mathrm{Cl})\end{array}$} & \multirow[t]{2}{*}{ P-value } & \multirow[t]{2}{*}{$\begin{array}{c}\text { AOR }(95 \% \\
\text { Cl) }\end{array}$} & \multirow[t]{2}{*}{ P-value } \\
\hline & & Adequate & Inadequate & & & & \\
\hline \multirow{5}{*}{$\begin{array}{l}\text { Occupation of Father } \\
(n=423)\end{array}$} & Employee(ref) & 144 & 57 & 1 & & 1 & \\
\hline & Merchant & 49 & 39 & $0.5(0.3-$ & 0.009 & $0.56(0.315-$ & 0.048 \\
\hline & & & & $0.84)$ & & $0.99)$ & \\
\hline & Others & 52 & 82 & $0.25(0.16-$ & $<0.001$ & $0.26(0.17-$ & $<0.001$ \\
\hline & & & & 0.40 & & $0.43)$ & \\
\hline \multirow[t]{5}{*}{ Watching TV } & Not at all (ref) & 15 & 39 & 1 & & 1 & \\
\hline & < once a week & 118 & 95 & $3.23(1.68-$ & $<0.001$ & 1.52(0.71- & 0.281 \\
\hline & & & & $6.2)$ & & $3.23)$ & \\
\hline & At least once a & 118 & 49 & $6.26(3.17-$ & $<0.001$ & $3.36(1.55-$ & 0.002 \\
\hline & week & & & 12.39) & & 7.3) & \\
\hline \multirow[t]{4}{*}{ Food security status } & Food secure & 187 & 66 & 5.18(3.423- & $<0.001$ & 5.09(3.2- & $<0.001$ \\
\hline & & & & 7.84) & & $8.08)$ & \\
\hline & Food insecure & 64 & 117 & 1 & & 1 & \\
\hline & (ref) & & & & & & \\
\hline
\end{tabular}

\section{Figures}

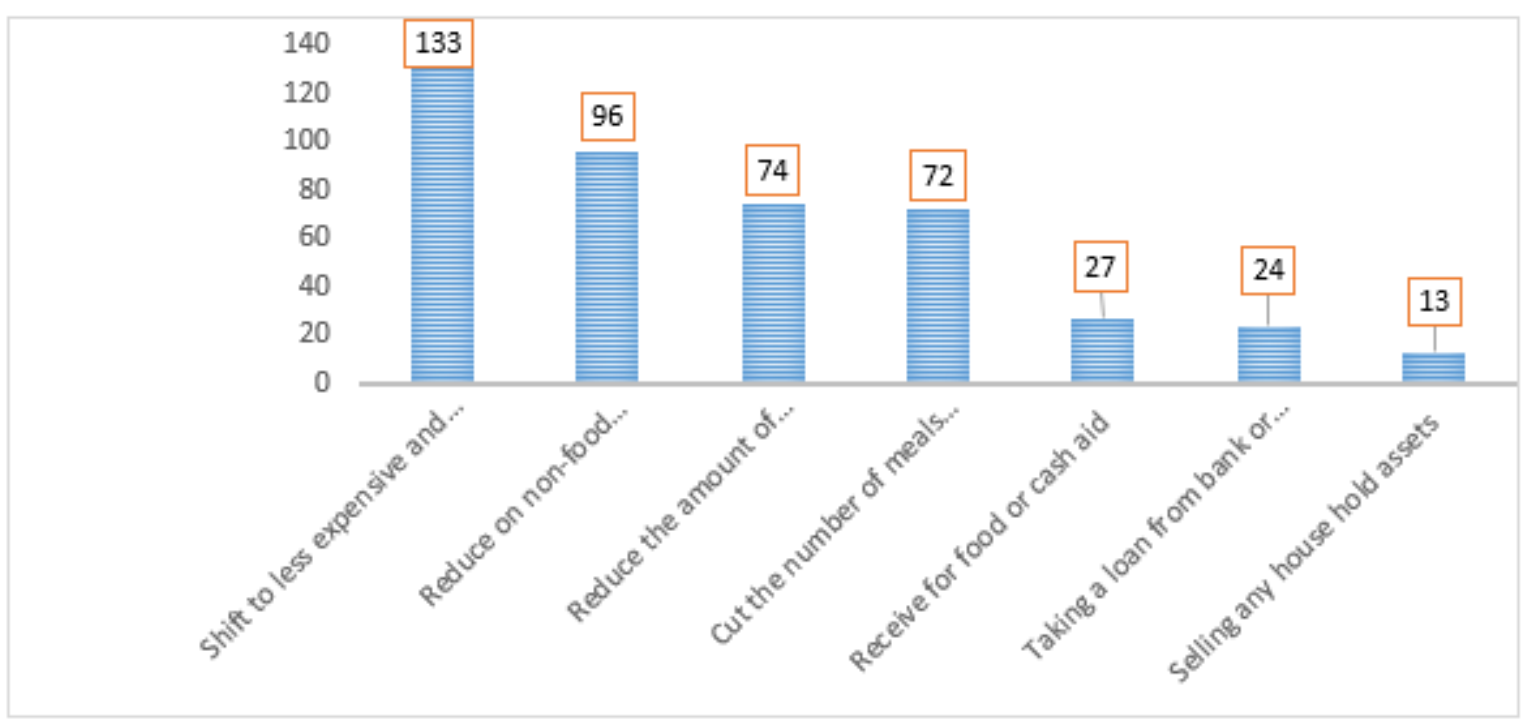

Figure 1 
Household coping strategies in response to food insecurity in Hossana Town, 2019. 